\title{
Starch nanoparticles in drug delivery: A review
}

\author{
Michael Ayodele Odeniyi ${ }^{A-F}, 0$ mobolanle A. Omoteso ${ }^{B-D}$, Adewale 0. Adepoju ${ }^{B-D}$, Kolawole T. Jaiyeoba ${ }^{\mathrm{E}, \mathrm{F}}$ \\ Department of Pharmaceutics and Industrial Pharmacy, University of Ibadan, Nigeria \\ A - research concept and design; $\mathrm{B}$ - collection and/or assembly of data; $\mathrm{C}$ - data analysis and interpretation; \\ $D$ - writing the article; $E$ - critical revision of the article; $F$ - final approval of the article
}

Address for correspondence

Michael Ayodele Odeniyi

E-mail: deleodeniy@gmail.com

Funding sources

None declared

Conflict of interest

None declared

Received on August 1, 2018

Reviewed on October 30,2018

Accepted on November 26, 2018

\begin{abstract}
The uptake and specificity of drugs and the bioavailability of poorly soluble drugs has been improved by means of targeted drug delivery using nanoparticles. Many platforms have been used for nanoparticulate drug delivery and these include liposomes, polymer conjugates, metallic nanoparticles, polymeric micelles, dendrimers, nanoshells, and protein and nucleic acid-based nanoparticles. Starch is the $2^{\text {nd }}$ most abundant natural polymer and has found wide use in drug delivery systems as binder, disintegrant and filler. However, its application is limited by the poor functional properties of native starch. Starch nanocrystals of different shapes and sizes can be obtained based on the starch origin and isolation process involved. Nanocrystals with varying morphology have been reported; from nanocrystals of platelet-like shaped waxy maize starch with 5-7 nm thickness and 15-40 nm diameters, to those with round and grape-like shape from potato starch granules, with sizes ranging from $40 \mathrm{~nm}$ to $100 \mathrm{~nm}$. This review describes different methods of obtaining starch nanoparticles, their modification and application in drug delivery.
\end{abstract}

Key words: drug delivery, starch modification, starch nanoparticles

Cite as

Odeniyi MA, Omoteso OA, Adepoju OA, Jaiyeoba KT.

Starch nanoparticles in drug delivery: A review.

Polim Med. 2018;48(1):41-45. doi:10.17219/pim/99993

DOI

10.17219/pim/99993

Copyright

( 2018 by Wroclaw Medical University

This is an article distributed under the terms of the

Creative Commons Attribution Non-Commercial License

(http://creativecommons.org/licenses/by-nc-nd/4.0/) 


\section{Introduction}

Nanoparticles, with a dimension range of 1-100 nm, are used as drug delivery systems. ${ }^{1,2}$ They are able to deliver a large quantity of substances to various sites of the body and for a longer time. In nanoparticle-based drug delivery, the most critical factors are particle size, particle surface properties, and the release of drugs or the active ingredients. ${ }^{3,4}$ The uptake and specificity of drugs and the bioavailability of poorly soluble drugs has been improved by means of targeted drug delivery using nanoparticles.,6 Several platforms have been used for nanoparticulate drug delivery. These include liposomes, polymer conjugates, metallic nanoparticles, polymeric micelles, dendrimers, nanoshells, and protein and nucleic acid-based nanoparticles. ${ }^{7-9}$ This review examines the use of starch nanoparticles in drug delivery, the effect of different methods of nanoparticle preparation and the effect of physical and chemical modifications of various starches on their functional properties and their potential for use as excipients in drug delivery.

\section{Starch}

Starch is one of the most abundant biomass materials in nature. ${ }^{10}$ Many plants store starch as a source of energy, as a natural, biocompatible, renewable, and biodegradable polymer. Starch is obtained from various classes of plants such as cereals or grains, roots, tubers, legumes, and fruits. Cereals have the highest percentage of starch. ${ }^{11}$ Plant cells synthesize starch in 2 forms of polymers: amylopectin and amylose. Amylopectin is made of linear chains of glucose units linked by $\alpha-1,4$ glycosidic bonds. It is highly branched at the $\alpha-1,6$ positions by small glucose chains at intervals of $10 \mathrm{~nm}$ along the molecule's axis and represents between $70 \%$ and $85 \%$ of common starch. ${ }^{12}$ Amylose is a linear chain of $\alpha-1,4$ glucans with partial branching points at the $\alpha-1,6$ positions and constitutes $15-30 \%$ of common starch. Wet grinding, sieving and drying are major ways of extracting and refining starch in the industry. It can be utilized in the natural form after extraction from plant "native starch" or undergo 1 or more modifications (physical, mechanical and/or chemical) to achieve targeted properties and become "modified starch".

\section{Starch nanoparticles}

Several components such as quantum dots, liposomes, starch, and other newly developed materials were used in the development of nanoparticle-based delivery systems. ${ }^{13-21}$ Nanoparticles, ${ }^{22}$ nanocolloids ${ }^{23}$ and nanocrystals ${ }^{24}$ have been prepared from starches.

Starch nanocrystals are derived from starch granule crystallites as a result of disrupting the semicrystalline structure of granules at temperatures below gelatinization temperature. ${ }^{25}$ Starch nanocrystals are also called starch crystallite, starch microcrystalline and hydrolyzed starch. It is important to note that starch nanocrystals are different from starch nanoparticles, which can be amorphous. While starch crystallite develops as a result of the disruption of non-crystalline domains from semi-crystalline granules by acid hydrolysis, starch nanoparticles are generated from congealed starch. ${ }^{26}$

Both the crystalline and non-crystalline regions coexist in the structure of the native starch but it is noteworthy to underscore the responsibility of the amylopectin chains in the formation of the crystalline regions due to the stacking of the nanometric sub-units of the amylopectin chain blocks, which eventually form the starch nanocrystals. ${ }^{27}$ As the native starch is subjected to acid hydrolysis, the starch granule begins to dissolve at the regions of low lateral order non-crystalline phases (amylose region), while changes do not occur at the highly crystalline water-insoluble lamellae. ${ }^{28}$

Le Corre et al. ${ }^{29}$ established that starches of the same amylose content but different botanical sources, e.g., maize, potato and wheat starches, show similar crystal size. However, differences in size were more pronounced with starches of the same botanical source but with different amylose content. This underlines the strong influence of the composition and molecular structure on the resulting crystallite dimensions that can be obtained when preparing starch nanocrystals. Low hydrolysis temperature ranging usually between $35^{\circ} \mathrm{C}$ and $45^{\circ} \mathrm{C}$ has been reported and is required to block starch congealing and consequent disruption of the starch crystalline structure. ${ }^{30}$

Starch nanocrystals of different shapes and sizes can be obtained depending on the starch origin and isolation process involved. Though the shape and size of the granules may vary between starches, there may be no discernable difference in the shape of starch nanocrystals from different sources. ${ }^{31} \mathrm{Xu}$ et al. ${ }^{24}$ found that the structure and morphology of obtained nanocrystals are influenced by several factors, such as the type of crystalline, amylose relative portion, amylopectin, botanical origin, and morphology of starch granule.

Nanocrystals with varying morphology and size have been reported. These include nanocrystals from plateletlike shaped waxy maize starch with 5-7 nm thickness and 15-40 nm diameter, ${ }^{32}$ to those from potato starch granules with round and grape-like shape ,with sizes ranging from $40 \mathrm{~nm}$ to $100 \mathrm{~nm}$ observed under transmission electron microscope (TEM). ${ }^{33}$

\section{Preparation protocols for starch nanocrystals}

Three different methods are used to prepare starch nanocrystals and other nanoparticles: acid or enzymatic hydrolysis, regeneration and mechanical treatment. ${ }^{34}$ Different protocols for the preparation of nanocrystals from 
starches are employed with their attending challenges, chief of which is low or limited percent yield even after prolonged (days) acid hydrolysis. Another challenge is related to the onion-like structure of starch which hinders its hydrolysis. ${ }^{31}$

\section{Acid hydrolysis kinetic}

Starch is hydrolyzed using either dilute $\mathrm{HCl}$ or dilute $\mathrm{H}_{2} \mathrm{SO}_{4}$ at $25-55^{\circ} \mathrm{C}$ for different durations to manufacture acid-thinned starches, microcrystalline starch or starch nanocrystals. ${ }^{35,36}$ All types of starch experience a 2-stage hydrolysis profile, comprising an initial fast hydrolysis step, presumably due to the hydrolysis of the non-crystalline regions of starch granules, and a $2^{\text {nd }}$ slower step, presumably due to the hydrolysis of the crystalline regions. ${ }^{37}$ The dense packing of the starch in the crystalline region, which does not allow for the penetration of $\mathrm{H}_{3} \mathrm{O}^{+} \mathrm{A}$, leads to the slower hydrolysis rate of the crystalline region. ${ }^{36}$

A theory suggested that the dense packing of the starch in the crystalline region which does not allow for the penetration of $\mathrm{H}_{3} \mathrm{O}^{+} \mathrm{A}$ led to the slower hydrolysis rate of the crystalline region. ${ }^{36}$ The other theory is based on the hydrolysis of the glycosidic bonds requiring a change or transformation from the chair to half-chair conformation which is required for hydrolysis of the bonds. This is an action that occurs slowly due to immobilization of the sugars in the starch crystallites. ${ }^{38,39}$

Some major factors affecting acid hydrolysis kinetics include time, acid type, acid concentration, and temperature. ${ }^{22}$ The rate of hydrolysis increases at a constant temperature of $50^{\circ} \mathrm{C}$ with increasing acid concentration. ${ }^{39}$ Another study assumed that the optimum temperature and acid concentration for starch nanocrystal production should be $40^{\circ} \mathrm{C}$ and $3.16 \mathrm{M}$, respectively. ${ }^{35}$

Acid concentration, extent of hydrolysis ${ }^{40}$ and the separation technique used have all been implicated in the low yield of nanocrystals from acid hydrolysis of starches. ${ }^{22,37,40}$ Le Corre et al. ${ }^{40}$ showed that starch nanocrystals are mixed with other microparticles and some nanocrystals were converted to sugar at the end of the production process. This fact results in the observed low yields. They suggested that the amount of starch nanocrystals in the final suspension may depend on the extent of hydrolysis. The study concluded that during the course of hydrolysis both micro- and nanoscale particles are present in the system. Also, differential centrifugation was not suitable for fractionation due to hydrogen bonding and different densities within starch granules. A continuous extraction technique such as microfiltration was suggested as the appropriate separation technique. ${ }^{40}$

A dispersion of uniform starch nanocrystals was obtained using another technique which combined hydrolysis process with ultrasonication. ${ }^{41}$ Breaking up the aggregates of nanoparticles formed through hydrogen bonds was observed to be effective by ultrasonic treatment at $60 \%$ vibration amplitude for $3 \mathrm{~min}$. However, the starch nanocrystals treated by ultrasonication may have decreased crystallinity.

An innovative solution to address the limitations of the current processes for generating starch nanocrystals was developed by Le Corre et al. ${ }^{42}$ It involved the use of a microfiltration unit equipped with ceramic membranes for the filtration of hydrolysates obtained from wheat starch. Microfiltration limited the conversion of starch nanocrystals into oligo- or monosaccharides. During the $1^{\text {st }}$ day of hydrolysis, the nanoparticles produced were more crystalline and mostly B-type particles. The critical factor in the development of nanocrystals from starch is to maintain the crystalline structure of the starch while completely removing the non-crystalline region of starch granules.

Practical application of SNCs acquired using the usual acid hydrolysis method is limited because the conventional preparation method is time-consuming and results in low yield. Ball milling is a cheap and environment-friendly physical processing method that has been confirmed capable of changing properties of starch.

\section{Enzymatic hydrolysis method}

This method involves the use of enzymes, such as $\alpha$-amylase, as a pretreatment to boost the efficiency of preparation. Starch nanocrystals were prepared from waxy rice starch with average diameters of $500 \mathrm{~nm}$ using selective enzymatic hydrolysis. ${ }^{42}$ Recent developments are now focused on this method with an aim to mitigate the limitations of acid hydrolysis of starches in the preparation of starch nanocrystals.

Enzyme treatment before acid hydrolysis has been proposed to in order decrease the duration of starch nanocrystals preparation. ${ }^{34}$ Studies have shown that nanocrystals with platelet-like structure and length of 20-40 nm with a thickness of 4-7 nm were produced using this method. ${ }^{43}$

\section{Regeneration method}

Starch nanoparticles have been obtained from starch solutions using precipitation with organic solvents. Ethanol was used to precipitate starch nanoparticles in the range of 50-100 nm from pre-cooked native starch. ${ }^{44}$

\section{Mechanical treatment method}

Mechanical and thermal treatment of starch granules can be used to generate starch nanoparticles. A simplified technique involving high-pressure homogenization method was proposed. ${ }^{23}$ A specially designed microfluidizer was used through which a $5 \%$ starch slurry was 
passed several times under high shear pressure. Starch particles of sizes reduced into the range between 3-6 $\mu \mathrm{m}$ and 10-20 nm were obtained after 20 passes.

By combining a high-pressure homogenization technique with mini-emulsion cross-linking, sodium trimetaphosphate cross-linked starch nanoparticles were produced. ${ }^{44}$ This method is environment-friendly because the mechanical treatment procedure is carried out within a water system. However, the efficiency process is limited as only low concentration starch slurry can be use processed for homogenization, thereby giving a relatively low yield.

\section{Common modifications to starch and starch nanoparticles}

Starch has limited application in industry because of poor solubility and high viscosity. Improvement in certain properties and the addition of more functional groups to starch is possible using chemical modifications. Glucose units making up the chain provide sites to be modified with multifunctional groups due to the abundant hydroxyl groups. Improvement of specific functions of the polymer and consequent applications of starch nanocrystals is the main objective of chemical modification. Three approaches have been commonly used for starch nanocrystals modification. These include modification with chemical reaction with small molecules, grafting onto polymer chains with coupling agents and grafting from polymer chains with polymerization of a monomer. ${ }^{45}$

Elemental analysis, infrared spectroscopy analysis (FTIR) and X-ray photoelectron spectrometry (XPS) can be used to prove that modification occurred. Monitoring changes in the morphology and size, solubility or polarity, surface properties, and thermal properties can also be used to determine the effects of chemical modification of starch nanocrystals. The integrity of the starch nanocrystal crystalline structure must be intact regardless of the modification method used.

\section{Conclusions}

There is an increased interest in applications of starch nanocrystal and nanoparticle derivatives as drug delivery platforms due to their biocompatibility, improved mechanical properties, thermal properties, barrier properties, absorption properties, and ability to be modified for specific functional properties.

\section{References}

1. Soppimath KS, Aminabhavi TM, Kulkarni AR, Rudzinski WE. Biodegradable polymeric nanoparticles as drug delivery devices. J Control Release. 2001;70(1-2):1-20.

2. Mohanraj VJ, Chen Y. Nanoparticles: A review. Trop J Pharm Res. 2006;5:561-573.

3. Vila A, Sanchez A, Tobio M, Calvo P, Alonso MJ. Design of biodegradable particles for protein delivery. J Control Release. 2002;78(1-3):15-24.
4. Mu L, Feng SS. A novel controlled release formulation for the anticancer drug paclitaxel $\left(\operatorname{Taxol}^{\circledR}\right)$ : PLGA nanoparticles containing vitamin E TPGS. J Control Release. 2003;86(1):33-48.

5. Ould-Ouali L, Noppe $M$, Langlois $X$, et al. Self-assembling PEG$\mathrm{p}(\mathrm{CL}-\mathrm{Co}-\mathrm{TMC})$ copolymers for oral delivery of poorly water-soluble drugs: A case study with risperidone. J Control Release. 2005;102(3):657-668.

6. Kipp JE. The role of solid nanoparticle technology in the parenteral delivery of poorly water-soluble drugs. Int J Pharm. 2004;284(1-2):109-122.

7. Pathak Y, Thassu D. Drug Delivery Nanoparticles Formulation and Characterization. Rijeka, Croatia: PharmaceuTech Inc.; 2009:1-393.

8. Zhang L, Gu FX, Chan JM, Wang AZ, Langer RS, Farokhzad OC. Nanoparticles in medicine: Therapeutic applications and developments. Clin Pharmacol Ther. 2008;83(5):761-769.

9. Davis ME, Chen ZG, Shin DM. Nanoparticle therapeutics: An emerging treatment modality for cancer. Nat Rev Drug Discov. 2008;7(9):771-782.

10. Smith AM. The biosynthesis of starch granules. Biomacromolecules. 2001;2(2):335-341.

11. Santana AL, Meireles MAA. New starches are the trend for industry applications: A review. Food Public Health. 2014;4:229-241.

12. Durrani CM, Donald AM. Physical characterization of amylopectin gels. Polymer Gels Networks. 1995;3(1):1-27.

13. Baptista PV. Cancer nanotechnology: Prospects for cancer diagnostics and therapy. Curr Cancer Ther Rev. 2009;4(5):80-88.

14. Kim JY, Lim ST. Preparation of nano-sized starch particles by complex formation with $n$-butanol. Carbohydr Polym. 2009;76:110-116.

15. Riehemann K, Schneider SW, Luger TA, Godin B, Ferrari M, Fuchs H. Nanomedicine - challenge and perspectives. Angew Chem Int Ed Engl. 2009;48(5):872-897.

16. Petros RA, DeSimone JM. Strategies in the design of nanoparticles for therapeutic applications. Nat Rev Drug Discov. 2010;9(8):615-627.

17. Bae KH, Chung HJ, Park TG. Nanomaterials for cancer therapy and imaging. Mol Cells. 2011;31(4):295-302.

18. Taylor A, Wilson KM, Murray P, Fernig DG, Levy R. Long-term tracking of cells using inorganic nanoparticles as contrast agents: Are we there yet? Chem Soc Rev. 2012;41(7):2707-2717.

19. Villalonga-Barber C, Micha-Screttas M, Steele BR, Georgopoulos A, Demetzos C. Dendrimers as biopharmaceuticals: Synthesis and properties. Curr Top Med Chem. 2008;8(14):1294-1309.

20. Clift MJ, Stone V. Quantum dots: An insight and perspective of their biological interaction and how this relates to their relevance for clinical use. Theragnostic. 2012;2(7):668-680.

21. Yamashita T, Yamashita K, Nabeshi H, et al. Carbon nanomaterials: Efficacy and safety for nanomedicine. Materials (Basel). 2012;5(2):350-363.

22. Singh V, Ali SZ. Properties of starches modified by different acids. Int J Food Properties. 2008;11:495-507.

23. Liu D, Wu, Q, Chen H, Chang PR. Transitional properties of starch colloid with particle size reduction from micro to nanometer. $J \mathrm{Col}-$ loid Interface Sci. 2009;339(1):117-124.

24. Xu Y, Ding W, Liu J, et al. Preparation and characterization of organic-soluble acetylated starch nanocrystals. Carbohydr Polym. 2010;80:1078-1084.

25. Dufresne A. Processing of polymer nanocomposites reinforced with polysaccharide nanocrystals. Molecules. 2010;15(6):4111-4128.

26. Le Corre D, Bras J, Dufresne A. Starch nanoparticles: A review. Biomacromolecules. 2010;11(5):1139-1153.

27. Gallant DJ, Bouchet B, Baldwin PM. Microscopy of starch: Evidence of a new level of granule organization. Carbohydr Polym. 1997:32:177-191.

28. Song S, Wang C, Pan Z, Wang X. Preparation and characterization of amphiphilic starch nanocrystals. J Appl Polym Sci. 2008;107(1):418-422.

29. Le Corre D, Bras J, Dufresne A. Influence of botanic origin and amylose content on the morphology of starch nanocrystals. J Nanopart Res. 2011;13:7193-7208.

30. Lin N, Huang J, Chang PR, Anderson DP, Yu JJ. Preparation, modification and application of starch nanocrystals in nanomaterials: A review. Nanomater. 2011. doi:10.1155/2011/573687 
31. Ghasemlou M, Taghi Gharibzehedi SM, Cran MJ. Preparation and characterization of starch nanocrystals. In: Starch-Based Blends, Composites and Nanocomposites. Visakh PM, Yu L, eds. London, UK: The Royal Society of Chemistry; 2016:60-108.

32. Putaux JL, Molina-Boisseau S, Momaur T, Dufresne A. Platelet nanocrystals resulting from the disruption of waxy maize starch granules by acid hydrolysis. Biomacromolecules. 2003;4(5):1198-1202.

33. Chen G, Wei M, Chen J, Huang J, Dufresne A, Chang PR. Simultaneous reinforcing and toughening: New nanocomposites of waterborne polyurethane filled with low loading level of starch nanocrystals. Polymer. 2008;49(7):1860-1870.

34. Le Corre D, Vahanian E, Dufresne A. Enzymatic pretreatment for preparing starch nanocrystals. Biomacromolecules. 2012;13(1):132-137.

35. Angellier H, Choisnard L, Molina-Boisseau S, Ozil P, Dufresne A. Optimization of the preparation of aqueous suspensions of waxy maize starch nanocrystals using a response surface methodology. Biomacromolecules. 2004;5(4):1545-1551.

36. Li W, Corke H, Beta T. Kinetics of hydrolysis and changes in amylose content during preparation of microcrystalline starch from highamylose maize starches. Carbohydr Polym. 2007;69:398-405.

37. Biliaderis CG, Grant DR, Vose JR. Structural characterization of legume starches I. Studies on amylose, amylopectin, and betalimit dextrins. Cereal Chem. 1981;58:496-502.

38. Whistler RL, BeMiller JN. Carbohydrate Chemistry for Food Scientists. St. Paul, MN: American Association of Cereal Chemists; 1997:1-140.

39. Wang Y-J, Truong V-D, Wang L. Structures and rheological properties of corn starch as affected by acid hydrolysis. Carbohydr Polym. 2003;52:327-333.

40. Le Corre D, Bras J, Dufresne A. Evidence of micro- and nanoscaled particles during starch nanocrystals preparation and their isolation. Biomacromolecules. 2011;8(12):3039-3046.

41. Kim HY, Lee JH, Kim JY, Lim WJ, Lim ST. Characterization of nanoparticles prepared by acid hydrolysis of various starches. Starch/Starke. 2012:64:367-373.

42. Le Corre D, Bras J, Dufresne A. Ceramic membrane filtration for isolating starch nanocrystals. Carbohydr Polym. 2011;86:1565-1572.

43. Dufresne A. Polysaccharide nanocrystals reinforced nanocomposites. Can J Chem. 2008;86(6):484-494.

44. Ma X, Jian R, Chang PR, Yu J. Fabrication and characterization of citric acid-modified starch nanoparticles/plasticized-starch composites. Biomacromolecules. 2008;9(11):3314-3320.

44. Shi AM, Li D, Wang LJ, Li BZ, Adhikari B. Preparation of starchbased nanoparticles through high-pressure homogenization and miniemulsion cross-linking: Influence of various process parameters on particle size and stability. Carbohydr Polym. 2011;83:1604-1610.

45. Angellier H, Putaux J-L, Molina-Boisseau S, Dupeyre D, Dufresne A. Starch nanocrystal fillers in an acrylic polymer matrix. Macromolecular Symposia. 2005;221:95-104. 
